\title{
EDITORIAL
}

\section{Enfermagem e a Pesquisa sobre Segurança dos Pacientes}

Nas últimas décadas a preocupação com a segurança no cuidado prestado ao paciente tem se tornado um dos assuntos prioritários na área da saúde, refletindo na busca e desenvolvimento de evidências científicas.

O assunto teve uma grande repercussão nos Estados Unidos da América, no final da década de 1990, a seguir alcançou países como Canadá, Espanha, Reino Unido, Austrália e na America Latina: Brasil, Perú, Argentina e Colômbia, a partir da publicação do relatório "To err is human" pelo Institute of Medicine dos Estados Unidos da América ${ }^{(1)}$.

Em 2002, na esteira da repercussão internacional, a Organização Mundial da Saúde (OMS) criou um grupo de trabalho com o objetivo de avaliar, de forma sistemática, a segurança do paciente nos serviços de saúde e definiu em 2005, o programa denominado Aliança Mundial para a Segurança do Paciente, que propôs diretrizes e estratégias para incentivar e divulgar, em diferentes países, práticas que garantissem a segurança dos pacientes e definir o desenvolvimento de pesquisas baseadas em evidências científicas com melhores práticas voltadas à segurança do paciente. Atualmente o termo usado pela OMS é Programa de Segurança do Paciente.

No Brasil, o final da década de 1990 e os primeiros anos da década de 2000 encontraram um ambiente propício para a incorporação de ações sobre segurança do paciente na assistência à saúde e, consequentemente, no desenvolvimento de investigações científicas.

Uma destas ações foi a criação, pelo Ministério da Saúde, no ano de 1999, da Agência Nacional de Vigilância Sanitária (ANVISA) com a missão de proteger e promover a saúde, garantindo a segurança sanitária dos produtos e serviços. Dentro da necessidade da ANVISA, de obter informação qualificada sobre o desempenho dos produtos de saúde utilizados no Brasil, criou-se a Rede Brasileira de Hospitais Sentinela. Essa rede de serviços tem a finalidade de notificar eventos adversos e queixas técnicas de produtos de saúde, sangue e hemoderivados, materiais e equipamentos médico hospitalares. Dentre as ações, que os hospitais da Rede Sentinela, deveriam implementar, estava a figura do gerente de risco, designado pela diretoria do hospital para atuar como elemento de ligação com a ANVISA e que teve um papel importante nas iniciativas nacionais sobre segurança do paciente nas instituições, ainda que esse não havia sido o propósito inicial .

Outra iniciativa interessante para o desenvolvimento de ações voltadas para a segurança do paciente foi a criação de comitês multidisciplinares nas instituições de saúde que articulassem e coordenassem programas e atividades de prevenção de eventos adversos, denominados Comitês de Qualidade ou Comitê de Farmácia e Terapêutica ou Comitê de Segurança do paciente ${ }^{(2)}$.Alguns hospitais privados lideraram essa iniciativa e influenciaram, com suas bem sucedidas experiências, os hospitais públicos. Tais comitês foram criados com a finalidade de promover uma cultura hospitalar voltada para a segurança de pacientes por meio de planejamento, desenvolvimento, controle e avaliação de processos assistenciais. Esses comitês, quando instituídos, estão, geralmente ligados à mais alta administração da instituição e muitos são liderados por enfermeiros.

Em 2005, a Unidade dos Recursos Humanos para a Saúde da Organização Pan-Americana da Saúde criou a Rede Internacional de Enfermagem e Segurança do Paciente, em Concepción- Chile, com o objetivo de traçar tendências e prioridades no desenvolvimento da enfermagem na área da Segurança do Paciente, discutir cooperação e intercâmbio de informações entre os países e necessidades de fortalecimento do cuidado de enfermagem a partir de evidencias científicas.

A Rede Brasileira de Enfermagem e Segurança do Paciente-REBRAENSP, criada em maio de 2008 foi a estratégia adotada por grupos de enfermeiros, para desenvolvimento de articulação e de cooperação entre instituições de saúde e educação, com o objetivo de fortalecer a assistência de enfermagem segura e com qualidade. É um bem sucedido e exemplar movimento social na 
enfermagem brasileira que, reconhecendo o seu papel na assistência à saúde, busca por cooperação, parceria e mudanças.

O trabalho dessa Rede foi difundido, através dos seus pólos, estaduais e municipais, cujo papel é o de divulgar os conceitos de segurança do paciente da OMS e de outras instituições, incentivar a criação e participação de enfermeiros em comitês de segurança do paciente e instituir, nos locais de trabalho, atitudes e iniciativas, com base científica, que diminuam os riscos e garantam a segurança do paciente, reconhecendo que os riscos são inerentes a qualquer processo de trabalho.

Atualmente a Organização Panamericana de Saúde trabalha a diretriz da qualidade do cuidado e a segurança do paciente com as seguintes linhas de ação: posicionar o tema como prioridade setorial embasado em evidencias científicas e análises econômicas; fomentar a participação comunitária facilitando a informação e conhecimento a pacientes e famílias; gerar informação e evidencias através de estudos de avaliação e de investigação e desenvolver, adaptar e apoiar soluções de qualidade desenvolvendo-as, compilando e as difundindo em modelos e ferramentas de qualidade.

E o futuro das investigações sobre segurança do paciente?

As investigações mais atuais sobre o tema e fundos de pesquisa internacionais tem se antecipado sobre a necessidade de os pesquisadores desenvolverem projetos que proponham, testem e avaliem as várias abordagens sobre simulação. A simulação, na assistência à saúde, é uma técnica de treinamento que coloca os indivíduos e equipes em desafios clínicos realistas através do uso de manequins, realidade virtual e outras formas de treinamento que permitam, aos participantes, vivenciarem, em tempo real, as consequencias de suas ações e decisões.

Considero que esse tema, não somente sob o prisma da educação de recursos humanos em saúde, mas aliado aos propósitos de melhoria da qualidade da assistência como uma recente e importante ação e direção que as pesquisas em segurança do paciente deverão tomar nos próximos anos.

\section{REFERÊNCIAS}

1. Kohn L, Corrigan J, Donaldson M, editors. To Err Is Human: Building a Safer Health System. Washington (DC): National Academies Press; 2001.

2. Cassiani SHB, editor. Hospitais e Medicamentos:impacto na segurança do paciente. Sao Paulo (SP): Yendis Editora; 2010.

Silvia Helena De Bortoli Cassiani

Professora Titular da Escola de Enfermagem de Ribeirão Preto da Universidade de São Paulo EERP-USP, Ribeirão Preto (SP), Brasil 